\title{
EARLY DETECTION OF ABNORMAL GROWTH ASSOCIATED WITH JUVENILE ACQUIRED HYPOTHYROIDISM USING SYSTEMATIC GROWTH MONITORING
}

\author{
Antti Saari, M.D., Ph.D. ${ }^{1}$, Jari Pokka, M.D. ${ }^{2}$, Outi Mäkitie, M.D., Ph.D. ${ }^{3,4,5}$, Marja-Terttu Saha, M.D., \\ Ph.D. ${ }^{6}$, Leo Dunkel, M.D., PhD. ${ }^{7}$ and Ulla Sankilampi, M.D., Ph.D. ${ }^{1}$ \\ AfFiliations: ${ }^{1}$ Department of Paediatrics, Kuopio University Hospital, Kuopio, Finland; ${ }^{2}$ Department of \\ Paediatrics, School of Medicine, University of Eastern Finland, Kuopio, Finland; ${ }^{3}$ Children's Hospital, \\ University of Helsinki and Helsinki University Hospital, Helsinki, Finland; ${ }^{4}$ Folkhälsan Research Centre, \\ Helsinki Finland; ${ }^{5}$ Department of Molecular Medicine and Surgery, Karolinska Institutet, Stockholm, \\ Sweden; ${ }^{6}$ Department of Paediatrics, Tampere University Hospital, Tampere, Finland; ${ }^{7}$ Centre for \\ Endocrinology, William Harvey Research Institute, Barts and The London School of Medicine and \\ Dentistry, Queen Mary University of London, London, United Kingdom
}

ADDRESS CORRESPONDENCE TO: Antti Saari, Department of Paediatrics, Kuopio University Hospital, PO BOX 100, FIN-70029 Kuopio, Finland [antti.saari@kuh.fi], +358 44277 3992, or Leo Dunkel, Centre for Endocrinology, William Harvey Research Institute, Barts and The London School of Medicine and Dentistry, Queen Mary University of London, London, United Kingdom [1.dunkel@ qmul.ac.uk], +44 20 78826235

SHORT TITLE: Abnormal growth and juvenile hypothyroidism

ABBREviations: AUC - area under curve; BMI - body mass index; fT4 - free thyroxine; HT - Juvenile acquired hypothyroidism; ROC - Receiver Operating Characteristic; THL - National Institutes of Health and Welfare; TSH - thyroid stimulating hormone; BMISDS - body mass index-for-age z-score; HSDS - heightfor-age z-score; $\triangle \mathrm{HfA}$ - change in height-for-age $\mathrm{z}$-score; $\mathrm{TH}^{\mathrm{DEV}} \mathrm{SDS}$ - height-for-age z-score deviation from target height

KEYWORDS: autoimmunity, child, growth, growth monitoring, hypothyroidism, screening, sensitivity, specificity

\section{KEY POINTS:}

Question: What is the longitudinal growth phenotype in children before diagnosis of juvenile acquired hypothyroidism, and could hypothyroidism be detected with systematic growth monitoring?

Findings: In this longitudinal study involving 109 children with juvenile acquired hypothyroidism, growth was abnormal up to 5 years before the diagnosis. The abnormal growth pattern could be recognized by systematic growth monitoring.

Meaning: Systematic growth monitoring may facilitate early diagnosis of hypothyroidism in children.

WORD COUNT: 2,849 


\section{AbStract}

Importance: Short stature and excessive weight gain are common features in children with juvenile acquired hypothyroidism (jHT). However, longitudinal growth characteristics preceeding the diagnosis of $\mathrm{jHT}$ have not been extensively studied, and it is unknown whether these children can be detected from the general population with systematic growth monitoring.

Objective: To characterize childhood growth pattern 5 years prior to jHT diagnosis and test the performance of auxological screening of $\mathrm{jHT}$.

Design and Setting: Retrospective longitudinal study analysis of growth of jHT patients (cases) against growth of healthy children (hundred age and sex matched control for each case) adjusting for confounding factors potentially affecting growth.

\section{Setting: Jos nyt aineiston alkuperän haluaa raportoida niin sitten erikseen tähän.}

Participants: 109 children with jHT (clinically diagnosed jHT and TSH > 10 mU/l) and their 554 height and weight measurements. Each case was paired with 100 healthy controls (i.e. 10,900 healthy children with 58,442 measurements). Tilastollinen vertailu omaan virkkeeseen: ....age $(P=0.826)$ and sex $(P=1.000)$

Main Outcome and Measure: Longitudinal growth data were converted into standard deviation scores and five different growth screening parameters were used (height-for-age [HSDS], HSDS deviation from target height $\left[\mathrm{TH}^{\mathrm{DEV}}\right.$ SDS], HSDS change over time [ $\triangle \mathrm{HSDS}$ ] body mass index-for-age [BMISDS] and BMISDS change over time [ $\triangle \mathrm{BMISDS}])$ and analyzed using mixed linear model. Accuracy of growth monitoring in jHT screening was evaluated using Receiver Operating Characteristics analysis.

Results: At diagnosis, children with jHT were significantly heavier (mean adjusted BMISDS difference 0.65 [95\% CI 0.46 to 0.84$])$, and shorter [mean adjusted $\mathrm{TH}^{\mathrm{DEv}} \mathrm{SDS}$ difference -0.34 (-0.57 to -0.10 ] than healthy children. Already 5 years before the diagnosis, jHT children were heavier [mean BMISDS difference 0.33 ( $95 \%$ CI 0.12 to 0.54 )] , but also taller [mean $\mathrm{TH}^{\mathrm{DEV}}$ SDS difference 0.29 (95\% CI 0.06 to 0.52 )] than healthy children. jHT could be detected within good accuracy when all the five growth parameters were used simultaneously in screening (area under curve 0.83 [95\% CI 0.78 to 0.89$]$ ]). 
Conclusions and Relevance: Growth of jHT children was abnormal up to 5 years before the diagnosis.

Systematic growth monitoring facilitates early diagnosis of $\mathrm{jHT}$, which is important for the neurocognitive development of the patients with jHT. 


\section{INTRODUCTION}

Thyroid hormones are crucial for normal childhood growth and development. They regulate linear growth directly at the growth plate but also enhance growth hormone secretion from the pituitary gland as well as potentiate its effects on target tissues. In the juvenile acquired hypothyroidism (jHT), slow linear growth together with excessive weight gain is regarded as the pathognomonic auxological sign of the condition. This typical growth pattern with or even without clinical symptoms such as fatigue, cold intolerance or obstipation, is an indication for thyroid function assessment. ${ }^{1,2}$ Despite the general understanding of the role of thyroid hormones in growth regulation, there are very little data on how the growth failure associated with jHT evolves over time. ${ }^{3}$ Early detection of jHT is important not only for the neurocognitive development but also for prevention of permanent height deficit related to the thyroid hormone deficiency. ${ }^{3}$

Childhood growth monitoring aims at early detection of disorders that affect growth, ideally at an early stage before any other signs or symptoms of the disease appear. Auxological screening is based on growth reference cut-off values. ${ }^{4-7}$ Recently, we and others have shown that auxological screening is a highly accurate tool for early diagnosis of Turner syndrome, ${ }^{4,7}$ and it facilitates the early diagnosis of celiac disease. ${ }^{6}$ However, the performance of growth screening in the detection of $\mathrm{jHT}$ has not been previously assessed.

We hypothesized that in jHT the pathognomonic growth pattern is detectable years before clinical symptoms of the disease. Therefore, systematic growth monitoring using robust population-specific cut-off values for abnormal growth may support timely diagnosis of jHT. In this study, we characterize the longitudinal growth pattern up to 5 years prior to the diagnosis of $\mathrm{jHT}$ and test the performance of auxological screening of the condition.

\section{PATIENTS AND METHODS}

Permissions for the current study were obtained from the Espoo Municipality Institutional Review Board and the National Institute of Health and Welfare (THL). The study was approved by the Ethics Committee of the Pohjois-Savo Health Care District. No contact was made with the study subjects; all the data were analyzed anonymously. 
$P$ values less than 0.05 were considered statistically significant. Data were analyzed using SPSS software (version 21, IBM Corporation, Armonk, NY).

\section{Children with juvenile autoimmune hypothyroidism}

All children and adolescents aged 0 to 18 years with diagnosis of jHT (International Classification for Diseases version 10 codes E03.3 - E03.9) were identified in patient registries of three University Hospitals in Finland (Helsinki, Kuopio and Tampere). For these children, clinical and laboratory data were collected retrospectively from the patient files. The age at diagnosis, symptoms at the onset of jHT and laboratory results (thyroid stimulating hormone [TSH], free thyroxine [fT4] and thyroid peroxidase autoantibodies [TPOAb]) were registered.

In Finland, all children are provided at least 24 routine visits at child well-fare clinics and school health care and measurements are captured in an electronic patient management system. The service has almost a full coverage in the Finnish child population. ${ }^{8}$ All weight and height data from these regular visits in primary care as well as from possible hospital visits and data on parental heights of the jHT patients were collected.

The initial jHT cohort comprised of 184 children (68\% girls) with 992 height and weight measurements (Figure 1). None of the children had congenital hypothyroidism. Children with any other condition or medication possibly affecting growth were excluded $(\mathrm{N}=70)$. These were congenital syndromes $(\mathrm{N}=32)$, type 1 diabetes $(\mathrm{N}=12)$, asthma $(\mathrm{N}=11)$, preterm birth or missing birth data $(\mathrm{N}=10)$, growth hormone deficiency $(\mathrm{N}=3)$, and celiac disease $(\mathrm{N}=2)$. The diagnosis of $\mathrm{jHT}$ was based on elevated serum $\mathrm{TSH} \geq 10 \mathrm{mIU} / \mathrm{l}$ at some point of the course of the disease. The cut-off of $10 \mathrm{mIU} / \mathrm{l}$ is generally regarded as criteria for $\mathrm{jHT}$ and an indication for levothyroxine treatment in children regardless of fT 4 or TPOAb levels ${ }^{9}$ Thus, 5 children with clinically diagnosed jHT with TSH levels $<10$ mIU/l were excluded. The final jHT cohort consisted of 109 children aged 1.2 to 16.2 years at diagnosis (median age 10.7 years; $75 \%$ girls).

Longitudinal growth data were divided into seven annual slots according to the time prior or after the diagnosis $(-5,-4,-3,-2,-1$ years prior to the diagnosis, time at diagnosis, and +1 year after the diagnosis). Only one height and weight measurement per child in one time-slot, closest to the exact full year, was 
included in the analyses. Altogether, 109 children with jHT children had 554 height and weight measurements during the 5 years preceding and 1 year following the jHT diagnosis (Table 1, Figure 1).

\section{Reference population and selection of controls matched for age and sex}

The population-based growth data of 32,592 healthy Finnish children and adolescents aged 0-20 years (16,039 girls and 16,553 boys) with 167,982 measurements comprised the reference population. These healthy children were measured in routine visits at well-baby clinics or school health care. Data collection of the reference population is described in detail elsewhere. ${ }^{5}$

Since higher proportion of jHT patients than of the reference population were girls ( $75 \%$ vs. $50 \%$ ), we chose a case-control design for our analyses and matched each of the $109 \mathrm{jHT}$ patients with 100 controls by age and sex. The matching resulted in the control population of 10,900 healthy subjects ( $75 \%$ girls) with 74,925 measurements (Table 1). Potentially false measurements, typing errors, missing values, or duplicated recordings were evaluated by scatter plots, and then either corrected or excluded. Accordingly, 74,925 measurements of the control population matched for age and sex were divided into 7 yearly time slots and duplicate measurements within any time slot were excluded (16,483 measurements).

\section{Growth monitoring parameters and statistical analysis}

Longitudinal height and weight measurements were transformed into the following standard deviation scores: height-for-age SDS (HSDS), HSDS deviation from target height SDS (TH ${ }^{\mathrm{DEv}}$ SDS), body mass index (BMI; calculated as weight in kilograms divided by height in meters squared) -for-age SDS (BMISDS), and changes in HSDS and BMISDS over time ( $\triangle$ HSDS, $\triangle$ BMISDS) using the contemporary Finnish growth references. ${ }^{4,5}$ The independent samples t-test was used for the comparison of normally distributed continuous parameters, and Mann-Whitney U-test as a non-parametric test, respectively. Categorical variables were compared using $\mathrm{X}^{2}$-test. A mixed linear model for repeated measurements was used to test the difference in the growth parameters between the jHT children and controls.

Several perinatal and neonatal factors obtained from the Finnish birth register for cases and controls were considered as potential covariates: ${ }^{10} 1$. maternal parity; 2. maternal smoking during pregnancy; 3 . mode of delivery; 4. birth weight; 5 . birth length; 6. plurality; 7. maternal age; 8 . gestational age at birth; and 9. 
season at birth (Supplemental Table 1). Birth length and weight were converted into SDS using the Finnish population based birth size reference ${ }^{11}$. The first six of these potentially confounding factors were taken account, because they showed statistically significant difference between cases with $\mathrm{jHT}$ and the matched controls in the mixed linear model.

The accuracy of the five growth monitoring parameters (HSDS, $\mathrm{TH}^{\mathrm{DEV}} \mathrm{SDS}$, BMISDS, $\triangle \mathrm{HSDS}, \triangle \mathrm{BMISDS}$ ) and their combination in auxological screening for $\mathrm{jHT}$ was tested using receiver operating characteristic curve (ROC) analysis. ROC analyses were based on the individual probability for abnormal growth calculated for each child in the jHT cohort and the control population using logistic regression. The results of the ROC analyses were classified based on area under curve (AUC) values as fail (AUC 0.50 to 0.59), poor (AUC 0.60 to 0.69 ), moderate (AUC 0.70 to 0.79 ), good (AUC 0.80 to 0.89 ) and excellent (AUC $0.90-1.00$ ).

\section{RESULTS}

The median age at $\mathrm{jHT}$ diagnosis was 10.6 years (range, 1.2 to 15.6 years). Altogether, 93 (85.3\%) jHT children had growth measurement at the time of diagnosis, $73(67.0 \%) 5$ years prior the diagnosis, and 83 (76.1\%) during the year following the diagnosis. At diagnosis, all the 109 children with $\mathrm{jHT}$ had TSH $\geq 10$ $\mathrm{mIU} / \mathrm{l}$ (the diagnostic criteria for jHT) with median TSH value of $36.7 \mathrm{mIU} / \mathrm{l}$ (range 10.2 to 1339.0; laboratory reference values 0.3 to $4.2 \mathrm{mIU} / \mathrm{l})$. In addition, 79 children $(72.5 \%)$ had fT4 below the normal range (median $8.40 \mathrm{pmol} / 1$ [range 0.01 to 18.00 ]; laboratory reference values 11 to $22 \mathrm{pmol} / \mathrm{l}$ ) and 75 children (68.8\%) were TPOAb positive (TPOAb > $6 \mathrm{IU} / \mathrm{ml}$, median $460 \mathrm{IU} / \mathrm{ml}$ (range 0 to 10625) (Table 1).

At diagnosis, children with jHT were shorter with significantly lower HSDS and $\mathrm{TH}^{\mathrm{DEV}} \mathrm{SDS}$, and heavier with significantly higher BMI SDS than the healthy controls (Table 1). However, the most pronounced difference was seen in linear growthin height in the time period of one year prior the diagnosis (mean unadjusted $\triangle$ HSDS difference from healthy controls -1.06 [95\% CI -1.34 to -0.79$]$ ).

The growth difference remained significant also after adjustments for perinatal confounders. The $\mathrm{TH}^{\mathrm{DEv}} \mathrm{SDS}$ difference between $\mathrm{jHT}$ children and healthy children was -0.35 [-0.58 to -0.11]) and BMISDS difference $0.65[0.45$ to 0.85$)]$ at the time of diagnosis. In addition, significantly slower linear growth was observed in the jHT children than in the controls already 2 years before the diagnosis (mean adjusted $\Delta$ HSDS difference 
-0.53 [95\% CI -0.80 to -0.26]) (Figure 2). In contrast to the shorter stature at the time of diagnosis, children with jHT were taller and already heavier than healthy controls 5 to 3 years earlier. The mean adjusted differences of $\mathrm{TH}^{\mathrm{DEv}}$ SDS and BMISDS between $\mathrm{jHT}$ patients and controls were 0.32 (95\% CI 0.07 to 0.58 ) and 0.44 (95\% CI 0.20 to 0.68$) 5$ years before the diagnosis. After 1 year of levothyroxine therapy, a complete catch-up growth, on average reaching the target height, had occurred (Figure 2).

Screening of abnormal growth in children with jHT using any of the growth parameters (HSDS, $\mathrm{TH}^{\mathrm{DEv}}{ }^{\mathrm{SDS}}$, BMISDS, $\triangle \mathrm{HSDS}$ or $\triangle \mathrm{BMISDS}$ ) alone yielded only poor to moderate accuracy (Figure 3). The accuracies (AUCs) varied from 0.56 (95\% CI 0.49 to 0.62 ) for HSDS to 0.70 (95\% CI 0.64 to 0.77 ) for $\Delta$ HSDS. However, when all five screening parameters were used in combination, growth failure of the $\mathrm{jHT}$ children was detected with a good accuracy (AUC $[95 \% \mathrm{CI}]=0.83[0.78-0.89])$ (Figure 3).

Performance of auxological screening of $\mathrm{jHT}$ and the comparison of three pre-defined growth parameter cutoff levels is shown in Table 2. If the cut-off level is set at -1.7 SD for height parameters (i.e. height parameter below $-1.7 \mathrm{SD}$ is abnormal) and above $+1.7 \mathrm{SD}$ for weight parameters, combination of all five parameters resulted in detection of $58 \%$ of jHT children (sensitivity 58\% [95\% CI 43 to $72 \%$ ]; specificity $87 \%$ [95\% CI 86 to $87 \%$ ]). For comparison, if the cutoff level +/- 2.7SD was chosen, the corresponding sensitivity was 25\% (95\% CI 13 to 39\%) and specificity 98\% (95\% CI 97 to 98\%) respectively. The best detection rate identifying abnormal growth in $\mathrm{jHT}$ children (sensitivity) using a single parameter was only $25 \%$ for $\triangle$ HSDS (95\% CI 15 to 37 ) using the cutoff level -1.7 SD

On odotettavissa ette refereet kysyvät TPO posit. Ja FT4 subnormal alaryhmien eroa niistä joilla ei ollutvasta-aineita tai matalaa FT4:a. Onko analysoitu?

\section{DISCUSSION}

In this study, we described, for the first time, the longitudinal growth pattern of a large cohort of $\mathrm{jHT}$ children from 5 years prior to the diagnosis to one year after the diagnosis. We observed that initially, these children are heavier as well as taller than their healthy pears. The pathognomonic growth failure observed at jHT diagnosis, i.e. height deflection together with excessive weight gain, evolves over time and may reflect the gradual development of thyroid hormone deficiency. Significant number of children diagnosed with jHT 
could have been detected by longitudinal growth monitoring and auxological screening with pre-established cut-off values, methods that are simple and non-invasive.

Our study demonstrated, for the first time, that the growth pattern in children with $\mathrm{jHT}$ is biphasic before the diagnosis. To our knowledge, there is only one small study with 13 subjects describing longitudinal growth in $\mathrm{jHT}$ children. ${ }^{3}$ The typical growth sign at the diagnosis of $\mathrm{jHT}$, the elevated weight and shorter than expected height, was seen in in the study by Rivkees et al as well as in our cohort ${ }^{3}$ In contrast to our study, they did not report growth in weight. Furthermore, they demonstrated incomplete catch-up growth after levothyroxine therapy, in contrast to good catch-up growth in our study. The observed differences might be due to their relatively small study cohort, possible differences in weight gain or timing of the diagnosis. Also, there was some methodological limitations possibly causing bias, such as lack of healthy controls and use of growth deflection as one of the inclusion criteria. ${ }^{3}$

In this study, children with $\mathrm{jHT}$ were heavier than healthy children already 5 years before diagnosis, and gained more weight closer to the diagnosis. Obesity may contribute to pathogenesis of several autoimmune disorders. ${ }^{12}$ Thyroid function may have a bidirectional association with childhood weight gain: ${ }^{13,14}$ obesity can lead to subclinical elevation of $\mathrm{TSH},{ }^{15}$ but also vice versa, a higher prevalence of thyroid autoimmunity has been observed in overweight children. ${ }^{16}$ Furthermore, excess weight gain in childhood has also been associated with autoimmune hypothyroidism in late adulthood. ${ }^{13}$ Thus, excess weight gain years before the onset of disease, as observed in the present cohort, might be an early sign for thyroid autoimmunity. The tall stature observed together with elevated weight years before the diagnosis of jHT might reflect, partially, the excess energy balance since weight gain in children is typically associated with rapid linear growth. ${ }^{17}$

Population-based growth monitoring programs aim at early detection of disorders that affect growth at an early stage of the condition. To our knowledge, this is the first study that has evaluated systematic growth monitoring in detecting children with jHT. We found that the best screening accuracy was accomplished if growth is monitored longitudinally rather than using one-off measurements, and by combining several growth parameters. However, the screening accuracy for jHT was not as good as has been achieved for Turner syndrome, ${ }^{4,7,18}$ but close to that we have previously shown for celiac disease. ${ }^{6}$ 
Lyhyt kappale siitä että tällainen seulonta on monimutkaista, mutta voidaan automatisøida olisi ilman munta tarpeen.

In the growth monitoring the cut-offs should ideally detect as many abnormally growing children as possible (i.e., high sensitivity) without producing too many referrals or investigations of healthy children (i.e., high specificity). The diagnostic accuracy of any screening program is always a trade-off between sensitivity and specificity. In jHT, a relatively low specificity can be considered acceptable because the detected children are investigated further using inexpensive and widely available thyroid function tests. For example, in the present study almost $60 \%$ of jHT children could be detected (sensitivity) if the abnormality for height parameters was defined as below $-1.7 \mathrm{SD}$ and weight parameters as above $+1.7 \mathrm{SD}$, and $13 \%$ of the healthy children that would have abnormal results in growth screening would not have had jHT (specificity 87\%). To us, these false-postive and false-negative rates seems acceptable.

A recent review revealed a large gap between the aims of the widespread implementation of growth monitoring, and the achieved level of early detection of growth disorders in children. ${ }^{19}$ Indeed, the preestablished screening cut-off values have not been implemented in most developed countries. ${ }^{19-23}$ In growth monitoring and screening, the main challenges are suboptimal methods ${ }^{19}$ which can result in both inappropriate referrals and delayed diagnosis. The cost-benefit- ratio of the auxological screening is also insufficiently explored. ${ }^{24,25}$ The most intensive growth monitoring programs including systematic screening for abnormal growth are established in Finland and the Netherlands. ${ }^{21,23} \mathrm{We}$ have recently shown that systematic growth monitoring facilitates early diagnosis of Turner syndrome and celiac disease. ${ }^{4,6}$ Furthermore, in this present study we demonstrated that a significant proportion of $\mathrm{jHT}$ children had grown abnormally before the diagnosis. The threshold for taking thyroid function laboratory tests is very low in the Finnish primary care, and we assume that most $\mathrm{jHT}$ cases are diagnosed considerably early in our population. Thus, growth screening accuracy could be even better in populations with a higher threshold for laboratory exams. 
The major strength of our study is the carefully examined relatively large cohort of jHT children and the large number of healthy matched controls. We could evaluate the longitudinal growth data starting from 5 years prior to the $\mathrm{jHT}$ diagnosis. Furthermore, data from the national birth register were available as a source of the potential confounding factors for linear growth.

A limitation of the study is the retrospective nature of the data. Thus, a prospective growth monitoring program in a population might provide different results. Furthermore, the observation of excessive weight gain in jHT children already 5 years before diagnosing may be biased because the thyroid hormone levels are more likely to be investigated in obese children. A prospective population-based study is warranted to evaluate the benefits and costs of growth monitoring program as well as confirm the observations of the longitudinal growth in jHT children.

\section{CONCLUSIONS}

In our study, children with jHT could be detected with a good screening accuracy using systematic growth monitoring. Thus, an early diagnosis of jHT may be facilitated by systematic growth monitoring combined to the examination of thyroid function tests. A challenge of the growth monitoring proposed by this study relates to the mathematical complexity of the screening algorithms. However, this can be overcome through the implementation of the screening rules into electronic health records systems - as already has been done in the Finnish primary care service production. ${ }^{26}$ In addition, children with jHT showed distinct longitudinal growth pattern of height and weight up to 5 years before diagnosis that may indicate early sign for thyroid autoimmunity, but however, its significance should be re-evaluated in further studies. 


\section{ACKNOWLEDGEMENTS}

\section{Author contributions:}

Antti Saari carried out the acquisition of the data, drafted the initial manuscript, and approved the final manuscript as submitted. He had full access to all of the data in the study and takes responsibility for the integrity of the data and the accuracy of the data analysis.

Jari Pokka carried out the initial analyses, and approved the final manuscript as submitted.

Outi Mäkitie carried out the data collection at one of the three sites, critically reviewed the manuscript, and approved the final manuscript as submitted.

Marja-Terttu Saha carried out the data collection at one of the three sites, critically reviewed the manuscript, and approved the final manuscript as submitted.

Leo Dunkel conceptualized and designed the study, designed the data collection instruments, and coordinated and supervised data collection, critically reviewed and revised the manuscript, and approved the final manuscript as submitted.

Ulla Sankilampi conceptualized and designed the study, critically reviewed and revised the manuscript, and approved the final manuscript as submitted.

\section{Additional Contributions:}

Marja-Leena Lamidi, MSc, assisted with the statistics

\section{Funding sources:}

This study was supported by The Finnish Funding Agency for Technology (AS, LD, US), The National Graduate School of Clinical Investigation (AS), Kuopio University Hospital State Research Funding (AS, US), The Päivikki and Sakari Sohlberg Foundation (AS, US), Sigrid Juselius Foundation (OM), Foundation for Pediatric Research (OM, US), Academy of Finland (OM), Folkhälsan Research Foundation (OM), and The Finnish Medical Foundation (US) 
Financial Disclosures:

The authors have nothing to disclose

\section{Conflict of Interests:}

The authors have nothing to disclose 


\section{REFERENCES}

1. Hanley P, Lord K, Bauer AJ. Thyroid Disorders in Children and Adolescents: A Review. JAMA Pediatr. 2016;170(10):1008-1019

2. Abbassi V, Rigterink E, Cancellieri RP. Clinical recognition of juvenile hypothyroidism in the early stage. Clin Pediatr (Phila). 1980;19(12):782-786.

3. Rivkees SA, Bode HH, Crawford JD. Long-term growth in juvenile acquired hypothyroidism: the failure to achieve normal adult stature. $N$ Engl J Med. 1988;318(10):599-602.

4. Saari A, Sankilampi U, Hannila ML, Saha MT, Makitie O, Dunkel L. Screening of turner syndrome with novel auxological criteria facilitates early diagnosis. J Clin Endocrinol Metab. 2012;97(11):E2125-32.

5. Saari A, Sankilampi U, Hannila ML, Kiviniemi V, Kesseli K, Dunkel L. New Finnish growth references for children and adolescents aged 0 to 20 years: Length/height-for-age, weight-for-length/height, and body mass index-for-age. Ann Med. 2011;43(3):235-248.

6. Saari A, Harju S, Makitie O, Saha MT, Dunkel L, Sankilampi U. Systematic growth monitoring for the early detection of celiac disease in children. JAMA Pediatr. 2015;169(3):e1525.

7. Grote FK, van Dommelen P, Oostdijk W, et al. Developing evidence-based guidelines for referral for short stature. Arch Dis Child. 2008;93(3):212-217.

8. Mäki P, Laatikainen T, Koponen P, Hakulinen-Viitanen T, LATE work group., eds. Lasten ja nuorten terveysseurannan kehittäminen, LATE-hanke (The development of health monitoring among children and the young, LATE-project, in Finnish). Helsinki: Finnish National Institute for Health and Welfare; 2008.

9. Jonklaas J, Bianco AC, Bauer AJ, et al. Guidelines for the treatment of hypothyroidism: prepared by the american thyroid association task force on thyroid hormone replacement. Thyroid. 2014;24(12):1670-1751.

10. Gissler M, Teperi J, Hemminki E, Merilainen J. Data quality after restructuring a national medical registry. Scand J Soc Med. 1995;23(1):75-80. 
11. Sankilampi U, Hannila ML, Saari A, Gissler M, Dunkel L. New population-based references for birth weight, length, and head circumference in singletons and twins from 23 to 43 gestation weeks. Ann Med. 2013;45(5-6):446-454.

12. Versini M, Jeandel PY, Rosenthal E, Shoenfeld Y. Obesity in autoimmune diseases: not a passive bystander. Autoimmun Rev. 2014;13(9):981-1000.

13. Ong KK, Kuh D, Pierce M, Franklyn JA, Medical Research Council National Survey of Health and Development Scientific and Data Collection Teams. Childhood weight gain and thyroid autoimmunity at age 60-64 years: the 1946 British birth cohort study. J Clin Endocrinol Metab. 2013;98(4):1435-1442.

14. Rotondi M, Magri F, Chiovato L. Thyroid and obesity: not a one-way interaction. J Clin Endocrinol Metab. 2011;96(2):344-346.

15. Knudsen N, Laurberg P, Rasmussen LB, et al. Small differences in thyroid function may be important for body mass index and the occurrence of obesity in the population. J Clin Endocrinol Metab. 2005;90(7):40194024.

16. Garcia-Garcia E, Vazquez-Lopez MA, Garcia-Fuentes E, et al. Thyroid Function and Thyroid Autoimmunity in Relation to Weight Status and Cardiovascular Risk Factors in Children and Adolescents: A Population-Based Study. J Clin Res Pediatr Endocrinol. 2016;8(2):157-162.

17. He Q, Karlberg J. Bmi in childhood and its association with height gain, timing of puberty, and final height. Pediatr Res. 2001;49(2):244-251.

18. van Buuren S, van Dommelen P, Zandwijken GR, Grote FK, Wit JM, Verkerk PH. Towards evidence based referral criteria for growth monitoring. Arch Dis Child. 2004;89(4):336-341.

19. Scherdel P, Dunkel L, van Dommelen P, et al. Growth monitoring as an early detection tool: a systematic review. Lancet Diabetes Endocrinol. 2016;4(5):447-456.

20. Hall DM. Growth monitoring. Arch Dis Child. 2000;82(1):10-15.

21. Ministry of Social Affairs and Health. Primary healthcare act 66/1972, Government degree on primary health care 380/2009. 
22. Scherdel P, Salaun JF, Robberecht-Riquet MN, et al. Growth monitoring: a survey of current practices of primary care paediatricians in Europe. PLoS One. 2013;8(8):e70871.

23. Schafer W, Kroneman M, Boerma W, et al. The Netherlands: health system review. Health Syst Transit. 2010;12(1):v-xxvii, 1-228.

24. Sisley S, Trujillo MV, Khoury J, Backeljauw P. Low incidence of pathology detection and high cost of screening in the evaluation of asymptomatic short children. J Pediatr. 2013;163(4):1045-1051.

25. Wit JM, Oostdijk W. Evaluation of asymptomatic short children. J Pediatr. 2013;163(5):1534-1535.

26. Sankilampi U, Saari A, Laine T, Miettinen PJ, Dunkel L. Use of electronic health records for automated screening of growth disorders in primary care. JAMA. 2013;310(10):1071-1072. 


\section{LEGENDS OF THE FIGURES}

Figure 1. Flow chart of the study population.

Figure 2. Mean (95\% CI) HSDS deviation target height SDS ( $\left.\mathrm{TH}^{\mathrm{DEV}} \mathrm{SDS}\right)$, body mass index SDS

(BMISDS) (panel A), and changes in HSDS and BMISDS over time ( $\triangle$ HSDS, $\triangle$ BMISDS) (panel B) in 109 jHT patients in comparison to 10,900 healthy controls (indicated as the zero line).

Figure 3. Screening accuracy of 5 growth monitoring parameters (height-for-age [HSDS], HSDS deviation from the target height $\left[\mathrm{TH}^{\mathrm{DEV}}\right.$ SDS], the changes in HSDS [ $\triangle \mathrm{HSDS}$, body mass index-for-age [BMISDS], and BMISDS [ $\triangle \mathrm{BMISDS}$ ] over time) and their combination in 109 children with juvenile hypothyroidism. Area under the curve (AUC) values and their 95\% CIs are shown. 
Table 1. Characteristics of the children with juvenile acquired hypothyroidism (jHT, N=109) at the time of diagnosis and the healthy control population $(\mathrm{N}=10,900)$ matched for age and sex.

\begin{tabular}{|c|c|c|c|}
\hline & $\begin{array}{l}\text { jHT } \\
(\mathrm{N}=109)\end{array}$ & $\begin{array}{l}\begin{array}{l}\text { Controls } \\
(\mathrm{N}=10,900)\end{array} \\
\end{array}$ & P-value \\
\hline Female sex, count (\%) & $82(75 \%)$ & $8200(75 \%)$ & 1.000 \\
\hline Age (years), median (range) & $10.6(1.2$ to 15.6$)$ & $10.6(0.5$ to 16.5$)$ & 0.826 \\
\hline Number of measurements per subject, median (range) & $5(2$ to 7$)$ & $6(1$ to 7$)$ & $<0.001$ \\
\hline Paternal height (cm), mean (SD) & $178.5(5.9)$ & $180.0(6.5)$ & 0.036 \\
\hline Maternal height (cm), mean (SD) & $165.7(6.0)$ & $166.1(5.9)$ & 0.608 \\
\hline Target height SDS, mean (SD) ${ }^{a}$ & $-0.13(0.64)$ & $0.00(0.66)$ & 0.089 \\
\hline Height-for-age SDS, mean (SD) $)^{b, c}$ & $-0.32(1.33)$ & $-0.02(1.06)$ & 0.008 \\
\hline Height-for-age SDS deviation from target height SDS, mean (SD) ${ }^{a, b, c}$ & $-0.29(1.31)$ & $-0.02(1.08)$ & 0.040 \\
\hline Height-for-age SDS change over time, mean (SD) ${ }^{b, d}$ & $-1.00(1.63)$ & $0.07(1.10)$ & $<0.001$ \\
\hline BMI-for-age SDS, mean (SD) $)^{\mathrm{b}, \mathrm{c}}$ & $0.72(1.18)$ & $-0.07(1.06)$ & $<0.001$ \\
\hline BMI-for-age SDS change over time, mean $(\mathrm{SD})^{\mathrm{b}, \mathrm{d}}$ & $0.33(1.05)$ & $-0.03(1.01)$ & 0.005 \\
\hline TSH (mIU/l), median (range) ${ }^{\mathrm{e}}$ & $36.7(10.2$ to 1339.0$)$ & NA & NA \\
\hline fT4 $(\mathrm{pmol} / \mathrm{l})$, median $(\text { range })^{\mathrm{e}}$ & $8.40(0.01$ to 18.00$)$ & NA & NA \\
\hline TPOAb (IU/ml), median (range) $)^{\mathrm{e}}$ & $460(0$ to 10625$)$ & NA & NA \\
\hline
\end{tabular}

${ }^{\mathrm{b}}$ Growth data were not available in 16 children with $\mathrm{jHT}$ at the time of diagnosis

${ }^{c}$ Finnish growth references ${ }^{5}$

${ }^{\mathrm{d}}$ Finnish reference values for height for-age SDS change (available from birth to 12 years of age) and BMI-for-age SDS change (available 2 to 12 years of age) over time ${ }^{4,6}$

'Laboratory reference values: TSH 0.3 to $4.2 \mathrm{mIU} / \mathrm{l}$, fT4 11 to $22 \mathrm{pmol} / \mathrm{l}$, and TPOAb $<6 \mathrm{IU} / \mathrm{ml}$

Abbrevations: fT4, free thyroxine; NA, not available; SDS, standard deviation score; TPOAb, Thyroid peroxidase antibodies; TSH, thyroid

stimulating hormone 
Table 2. Performance of auxological screening for juvenile hypothyroidism using pre-defined cut-off levels I , II and III for abnormal growth: below -1.7 SD (I), -2.0 SD (II) or -2.7 SD (III) for height parameters, and above +1.7 SD (I), +2.0 SD (II) or +2.7 SD (III) for weight parameters among 109 children with juvenile hypothyroidism and 10900 healthy controls.

\begin{tabular}{|c|c|c|c|c|c|c|}
\hline & \multicolumn{2}{|c|}{ Cut-off level I ( \pm 1.7 SD) } & \multicolumn{2}{|c|}{ Cut-off level II ( \pm 2.0 SD) } & \multicolumn{2}{|c|}{ Cut-off level III ( \pm 2.7 SD) } \\
\hline Growth monitoring parameter & $\begin{array}{l}\text { Sensitivity } \\
\text { (95\% CI) }\end{array}$ & $\begin{array}{l}\text { Specificity } \\
(95 \% \text { CI })\end{array}$ & $\begin{array}{l}\text { Sensitivity } \\
\text { (95\% CI) }\end{array}$ & $\begin{array}{l}\text { Specificity } \\
\text { (95\% CI) }\end{array}$ & $\begin{array}{l}\text { Sensitivity } \\
\text { (95\% CI) }\end{array}$ & $\begin{array}{l}\text { Specificity } \\
\text { (95\% CI) }\end{array}$ \\
\hline $\mathrm{HSDS}^{\mathrm{a}}$ & $16.1(9.3$ to 25.2$)$ & $94.2(93.7$ to 94.7$)$ & $8.6(3.8$ to 16.3$)$ & $97.0(96.6$ to 97.4$)$ & $5.4(1.8$ to 12.1$)$ & 99.5 (99.3 to 99.6$)$ \\
\hline $\mathrm{TH}^{\mathrm{DEV}} \mathrm{SDS}^{\mathrm{b}}$ & $11.8(5.2$ to 21.9$)$ & 94.1 (93.6 to 94.6$)$ & $8.8(3.3$ to 18.2$)$ & 96.7 (96.4 to 97.1$)$ & $4.4(0.9$ to 12.4$)$ & $99.4(99.2$ to 99.5$)$ \\
\hline$\Delta \mathrm{HSDS}^{\mathrm{c}}$ & $25.0(15.0$ to 37.4$)$ & $95.4(94.8$ to 95.9$)$ & $21.9(12.5$ to 34.0$)$ & 97.5 (97.1 to 97.9$)$ & $14.1(6.6-25.0)$ & 99.4 (99.2 to 99.6$)$ \\
\hline BMISDS $^{\mathrm{a}}$ & 23.9 (15.6 to 33.9$)$ & 94.1 (93.5 to 94.6$)$ & $15.2(8.6$ to 24.2$)$ & $97.3(97.0$ to 97.7$)$ & $4.3(1.2$ to 10.8$)$ & 99.7 (99.6 to 99.8$)$ \\
\hline$\triangle \mathrm{BMISDS}$ & $7.9(2.6$ to 17.6$)$ & 95.4 (94.9 to 95.9$)$ & $4.8(1.0$ to 13.3$)$ & $97.4(97.0$ to 97.8$)$ & $1.6(0.0$ to 8.5$)$ & 99.3 (99.1 to 99.5$)$ \\
\hline \multicolumn{7}{|l|}{ Combined parameters } \\
\hline BMISDS or $\Delta \mathrm{HSDS}^{\mathrm{a}, \mathrm{c}}$ & $45.2(32.5$ to 58.3$)$ & 89.7 (88.9 to 90.4$)$ & 30.7 (19.6 to 43.7$)$ & 95.1 (94.5 to 95.6$)$ & $16.1(8.0$ to 27.7$)$ & 99.2 (98.7 to 99.2$)$ \\
\hline Any of the five parameters ${ }^{a, b, c}$ & $58.3(43.2$ to 72.4$)$ & $86.6(85.7$ to 87.4$)$ & $54.2(27.6$ to 56.8$)$ & $88.2(87.4$ to 89.0$)$ & 27.1 (15.3 to 41.9$)$ & 97.8 (97.4 to 98.2$)$ \\
\hline
\end{tabular}

Any of the five parameters ${ }^{\mathrm{a}, \mathrm{b}, \mathrm{c}}$

binnish target height formula

${ }^{c}$ Finnish reference values for height for-age SDS change (available from birth to 12 years of age) and BMI-for-age SDS change (available 2 to 12 years of age) over time ${ }^{4,6}$ 